\title{
Clinical factors associated with composition of lung microbiota and important taxa predicting clinical prognosis in patients with severe community-acquired pneumonia
}

\author{
Sisi $\mathrm{Du}^{1,2,3, *}$, Xiaojing $\mathrm{Wu}^{1,2,3, *}$, Binbin $\mathrm{Li}^{1,2,3, *}$, Yimin Wang ${ }^{1,2,3, *}$, Lianhan Shang ${ }^{1,2,3,4, *}$, Xu Huang ${ }^{1,2,3}$, Yudi Xia ${ }^{1,2,3}$, \\ Donghao $\mathrm{Yu}^{1,2,3,5}$, Naicong Lu ${ }^{1,2,3}$, Zhibo Liu ${ }^{1,2,3}$, Chunlei Wang ${ }^{1,2,3}$, Xinmeng Liu ${ }^{1,2,3}$, Zhujia Xiong ${ }^{1,2,3}$, Xiaohui Zou ${ }^{1,2,3}$, \\ Binghuai Lu ${ }^{1,2,3}$, Yingmei Liu ${ }^{1,2,3}$, Qingyuan Zhan $(\bowtie)^{1,2,3}$, Bin Cao $(\bowtie)^{1,2,3,6}$ \\ ${ }^{1}$ China-Japan Friendship Hospital, National Clinical Research Center for Respiratory Diseases, National Center for Respiratory Medicine, \\ Clinical Center for Pulmonary Infections, Capital Medical University, Beijing 100029, China; ${ }^{2}$ Institute of Respiratory Medicine, Chinese \\ Academy of Medical Sciences, Peking Union Medical College, Beijing 100029, China; ${ }^{3}$ Department of Pulmonary and Critical Care \\ Medicine, Center for Respiratory Diseases, China-Japan Friendship Hospital, Beijing 100029, China; ${ }^{4}$ Beijing University of Chinese \\ Medicine, Beijing 100029, China; ${ }^{5}$ Beijing Luhe Hospital, Beijing 101100, China; ${ }^{6}$ Tsinghua University-Peking University Joint Center for \\ Life Sciences, Beijing 100084, China
}

(C) Higher Education Press 2021

\begin{abstract}
Few studies have described the key features and prognostic roles of lung microbiota in patients with severe community-acquired pneumonia (SCAP). We prospectively enrolled consecutive SCAP patients admitted to ICU. Bronchoscopy was performed at bedside within $48 \mathrm{~h}$ of ICU admission, and 16S rRNA gene sequencing was applied to the collected bronchoalveolar lavage fluid. The primary outcome was clinical improvements defined as a decrease of 2 categories and above on a 7-category ordinal scale within 14 days following bronchoscopy. Sixtyseven patients were included. Multivariable permutational multivariate analysis of variance found that positive bacteria lab test results had the strongest independent association with lung microbiota $\left(R^{2}=0.033 ; P=0.018\right)$, followed by acute kidney injury $\left(A K I ; R^{2}=0.032 ; P=0.011\right)$ and plasma MIP-1 $\beta$ level $\left(R^{2}=0.027 ; P=0.044\right)$. Random forest identified that the families Prevotellaceae, Moraxellaceae, and Staphylococcaceae were the biomarkers related to the positive bacteria lab test results. Multivariable Cox regression showed that the increase in $\alpha$-diversity and the abundance of the families Prevotellaceae and Actinomycetaceae were associated with clinical improvements. The positive bacteria lab test results, AKI, and plasma MIP-1ß level were associated with patients' lung microbiota composition on ICU admission. The families Prevotellaceae and Actinomycetaceae on admission predicted clinical improvements.
\end{abstract}

Keywords severe community-acquired pneumonia; lung microbiota; clinical improvements; 7-category ordinal scale; Prevotellaceae

\section{Introduction}

Community-acquired pneumonia (CAP) is the leading reason of hospitalization worldwide, which claims thousands of lives each year [1]. Severe community-acquired

Received October 14, 2020; accepted April 15, 2021

Correspondence: Qingyuan Zhan, drzhanqy@163.com; Bin Cao, caobin_ben@163.com

${ }^{*}$ These five authors contributed equally to this work. pneumonia (SCAP) refers to patients complicated with severe hypoxemia, sepsis/septic shock, and acute respiratory distress syndrome (ARDS), who often require intensive care and mechanical ventilation [2,3]. Although broad-spectrum antibiotics and advanced oxygen support are used commonly as the therapeutic regimen, the mortality among SCAP patients remains as high as $25 \%-$ $50 \%[4,5]$.

Next-generation sequencing has revealed that the human lung contains complex and dynamic microbiota community [6]. The composition of lung microbiota in SCAP patients is complex and susceptible to changes during 
disease progression. The overgrowth of the invasive pneumonia-associated pathogens in patients' lower respiratory tract may cause a decline in lung microbiota diversity, and the microbiota might even be dominated by single species [7]. Based on the new conceptual models of respiratory microbiology proposed by Robert P Dickson, the lung microbiota is determined by three factors, namely, microbial immigration, elimination, and the relative reproduction rates of the members, which are affected by the regional growth conditions such as oxygen tension, $\mathrm{pH}$, alveolar ventilation, and temperature in the lung $[8,9]$. Critical illness alters the internal environment and pathophysiology of the respiratory tract in patients with SCAP. Laryngeal dysfunction, supine positioning, aspiration or confusion, and intensive care unit (ICU) management, including antibiotic use, mechanical ventilation, and vasopressors, affect the balance of the immigration and elimination of airway microorganisms [10]. Collectively, these clinical parameters have the potential to change the lung microbial composition of SCAP patients.

The relationship between respiratory microbial composition and respiratory infections has attracted increasing research and clinical interests. Recently, several studies have suggested that the lung microbiota is associated with respiratory infection and disease outcomes. The murine model suggests that the intact microbiota contributes to the protection against bacterial pathogens with GM-CSF signaling [11]. The sputum microbial composition is associated with the length of stay and ICU admission in children hospitalized for CAP [12]. Moreover, the enrichment of specific taxon in the airway microbiota, such as Enterobacteriaceae, might be related to high plasma inflammatory cytokine level and the development of ARDS, which indicate fewer ventilator-free days in patients with critical illness $[13,14]$. Although previous studies have identified that factors such as elder age, underlying diseases, and immunocompromised status predicted poor prognosis of SCAP patients [15], the prognostic role of lung microbiota in SCAP patients remains unclear.

As few studies have described the key features and prognostic roles of the lung microbiota in patients with SCAP, we conducted a study to explore the clinical factors that may be associated with the lung microbiota in patients with SCAP and identify the important taxa that may predict clinical prognosis.

\section{Materials and methods}

\section{Study populations}

All patients with SCAP admitted in ICU between March 2018 and March 2019 were prospectively enrolled in this observational study. The inclusion criteria were as follows: (1) age $\geqslant 18$ years; (2) diagnosed with SCAP according to the 2007 Infectious Disease Society of America/ American Thoracic Society guidelines (Table S1) [16]; (3) time from illness onset to ICU admission $\leqslant 7$ days; for patients transferred to ICU from normal wards in our hospital because of disease exacerbation within 7 days of hospital admission, the time from illness onset to ICU admission can be extended to 14 days (Fig. 1). Patients were excluded if they met one of the following criteria: (1) having a history of hospitalization within 14 days before illness onset; (2) bronchoscopy couldn't be performed within $48 \mathrm{~h}$ after admission to ICU; (3) peripheral blood specimens were not available within $24 \mathrm{~h}$; (4) pregnant or breastfeeding women; (5) had an alternative diagnosis at the end of the study, including lung cancer, pulmonary tuberculosis, or pulmonary embolism.

\section{Sample collection}

Bronchoscopy was performed at bedside within $48 \mathrm{~h}$ of ICU admission using the standard clinical protocol [17]. The bronchoscope was inserted through the nose or orotracheal tube, and the bronchoalveolar lavage fluid (BALF) samples were collected. Approximately $15 \mathrm{~mL}$ of BALF specimen was immediately sent to the microbiology laboratory for routine bacterial, fungal, and viral examinations, and the remaining BALF was stored at $-80^{\circ} \mathrm{C}$ until further processing. Blood samples were obtained within $24 \mathrm{~h}$ of ICU admission. The blood samples were centrifuged, and the remaining plasma was stored at $-80{ }^{\circ} \mathrm{C}$.

\section{S rRNA gene sequencing}

DNA was extracted from BALF and negative control using the Maxwell ${ }^{\mathbb{B}}$ RSC Whole Blood DNA Kit (Promega, USA). The V3-V4 hypervariable region of the 16S rRNA gene of all samples was amplified by polymerase chain reaction (PCR). The pooled library was sequenced on the Illumina Miseq platform (Illumina, San Diego, CA, USA) using pair-end sequencing $(2 \times 300 \mathrm{bp})$. Details are shown in the supplementary material.

\section{Data collection}

The following data of included patients were collected using a standard case report form: demographic data, underlying diseases, the time of illness onset, clinical symptoms, laboratory findings, microbiology results, radiographic data, antimicrobial use, glucocorticoid use, and mechanical ventilation use. The included patients were followed up until discharged or until the patient died, whichever happened first. 


\section{Cytokine measurement}

The plasma interleukin-4 (IL-4), IL-6, IL-8, macrophage inflammatory protein-1 $\beta$ (MIP-1 $\beta$ ), vascular endothelial growth factor-A (VEGF-A), and matrix metalloproteinase9 (MMP-9) of the included SCAP patients were detected using a magnetic bead-based multiplex immunoassay and read on a Bio-Plex 200 suspension array system (Bio-Rad, Hercules, CA, USA) according to the manufacturer's instructions.

\section{Definitions and outcomes}

The primary outcome was the rate of clinical improvements, which was defined as a decrease of 2 categories and above on a 7-category ordinal scale within 14 days following bronchoscopy. The ordinal scales, which were also used in our influenza and COVID-19 studies, consisted of the following categories: (1) not hospitalized with resumption of normal activities; (2) not hospitalized, but unable to resume normal activities; (3) hospitalization, not requiring supplemental oxygen; (4) hospitalization, requiring supplemental oxygen; (5) hospitalization, requiring nasal high-flow oxygen therapy and/or noninvasive mechanical ventilation; (6) hospitalization, requiring extracorporeal membrane oxygenation and/or invasive mechanical ventilation; (7) death [18-20]. In our study, immunocompromised status was defined as meeting any of the following conditions: having a history of cancer with neutropenia (neutrophil count $<0.5 \times 10^{9} / \mathrm{L}$ ), hematological malignancies, solid malignancies receiving chemotherapy during the previous 3 months, solid organ or bone-marrow transplant, active graft-versus-host disease, bronchiolitis obliterans, human immunodeficiency virus infection, immunoglobulin deficiency, using immunosuppressive agents, or current treatment with systemic corticosteroids $(\geqslant 20 \mathrm{mg}$ of prednisone per day or its equivalent) for $>30$ continuous days before illness onset [21]. The presence of ARDS on admission was diagnosed according to the Berlin definition [22]. For nonventilated subjects who had a history of acute respiratory failure within 7 days because of a known respiratory event and bilateral pulmonary infiltration on chest X-ray with $\mathrm{PaO}_{2} /$ $\mathrm{FiO}^{2}$ below $300 \mathrm{mmHg}$, ARDS was also diagnosed. Sepsis and septic shock were diagnosed on the basis of the third international consensus [23]. Acute kidney injury (AKI) was diagnosed on the basis of the Kidney Disease Improving Global Guidelines (KDIGO) [24]. Acute cardiac failure was diagnosed by cardiologists on the basis of clinical vitals, laboratory findings, and echocardiography. Pneumonia severity was assessed by CURB65, APACHE-II, and PSI risk class. For patients admitted to ICU on the same day, the order of performing bronchoscopy was arranged according to the time of signing the bronchoscopy informed consent.

\section{Microbial laboratory tests}

All the specimens for diagnostic microbiology were collected within $48 \mathrm{~h}$ after ICU admission. Virus laboratory tests were considered positive if the respiratory virus was detected in sputum, endotracheal aspirates (ETA), BALF, or nasopharyngeal (NP) swabs by real-time PCR (Zhijiang, Shanghai, China), including respiratory syncytial virus, influenza virus types A and B, parainfluenza virus, rhinovirus, coronavirus, human metapneumovirus, and adenovirus. Positive bacteria or atypical pathogen laboratory test results were defined as meeting one of the following criteria: (1) positive bacterial culture in the blood or pleural fluid sample; (2) positive antigen test for Legionella pneumophila (Binax Now; Trinity Biotech, Bray, Ireland) or Streptococcus pneumoniae (Binax Now; Emergo Europe, Amsterdam, The Netherlands) in urine sample; (3) identification of Mycoplasma pneumoniae or Chlamydia pneumoniae in sputum, BALF, ETA, or NP swabs by real-time PCR (Zhijiang, Shanghai, China); (4) identification of L. pneumophila in sputum, BALF, or ETA by real-time PCR (Zhijiang, Shanghai, China); (5) bacteria with moderate-to-heavy growth $(>3+$ growth) in qualified sputum or ETA or quantified culture in BALF of $\geqslant 10^{4} \mathrm{CFU} / \mathrm{mL}$ [21]. The diagnosis of invasive fungal disease (IFD) was based on the revision and update of the consensus definitions of IFD [25].

\section{Statistical analysis}

The software VSEARCH (version 2.7.1) and USEARCH (version 10.0) were used to process the sequencing data. Reads were denoised into Zero-radius Operational Taxonomic Units (ZOTUs) with UNOISE3. Contaminants and ZOTUs were identified by decontam package or comparison with the control samples (Table S2). A total of 490 ZOTUs were analyzed after removal of contaminants and ZOTUs whose relative abundance was less than $0.01 \%$. Statistical analysis was performed in $\mathrm{R}$ version 3.6.2 via the Rstudio interface. PERMANOVA (vegan R-package) based on the Bray-Curtis distance was performed to assess the association between the clinical factors and the lung microbiota. A random forest learning approach (randomForest R-package) was used to identify the clinical factors associated with taxon. The Wilcoxon rank sum test and generalized linear models were performed to compare the relative abundance of the species. Multivariable Cox regression was performed to assess the association between lung microbiota and clinical improvements. The Cox regression model was adjusted for sampling season, plasma IL-8 level, CURB-65, APACHEII scores, presence of shock at sampling, oxygen index on admission, creatinine level, and microbiology results. Detailed statistical analysis was described in the supplementary material. 


\section{Data access}

The sequence data have been deposited in the NCBI Sequence Read Archive under accession PRJNA616057. Feature, taxonomy, metadata tables, and a reproducible workflow of the analysis are available for download at related website.

\section{Results}

\section{Patients' characteristics and bacterial profiles}

A total of 67 patients were included (Table 1), and the study flowchart is depicted in Fig. 1. The median age of study patients was 64 years. Fifty $(74.63 \%)$ patients in the study population were male. Sixteen $(23.88 \%)$ patients were current smokers, and 10 patients $(14.93 \%)$ were in immunocompromised status. The sampling season was winter $(27 / 67,40.3 \%)$. Twenty-four $(35.82 \%)$ patients had a decrease of 2 categories and above on a 7-category ordinal scale within 14 days, and the average number of days was 9.54 days. Forty (59.7\%) patients had a decrease of 1 category and above on a 7-category ordinal scale within 14 days, and the average number of days was 6.8 days. The distribution of patients in each changed category ordinal from day 1 to 14 is shown in Fig. S1. A total of 67 BALF samples from the patients were analyzed. Proteobacteria was the most abundant phylum in the lung

Table 1 Baseline characteristics of the patients

\begin{tabular}{|c|c|c|c|c|}
\hline Variable & All patients $(N=67)$ & Improvement $(n=24)$ & Unimprovement $(n=43)$ & $P$ \\
\hline$\overline{\text { Age, year, median (IQR) }}$ & $64(22)$ & $56(16.5)$ & $67(23)$ & 0.07 \\
\hline Male, $n(\%)$ & $50(74.63)$ & $17(70.83)$ & $33(76.74)$ & 0.59 \\
\hline \multicolumn{5}{|l|}{ Smoking status ${ }^{\mathrm{a}}$} \\
\hline Current smoker, $n(\%)$ & $16(23.88)$ & $8(33.33)$ & $8(18.6)$ & 0.34 \\
\hline Former smoker, $n(\%)$ & $19(28.36)$ & $5(20.83)$ & $14(32.56)$ & \\
\hline Nonsmoker, $n(\%)$ & $32(47.76)$ & $11(45.83)$ & $21(48.84)$ & \\
\hline Drinking history, $n(\%)$ & $13(19.4)$ & $7(29.17)$ & $6(13.95)$ & 0.24 \\
\hline Immunocompromised status, $n(\%)$ & $10(14.93)$ & $5(20.83)$ & $5(11.63)$ & 0.51 \\
\hline Chronic respiratory disease, $n(\%)$ & $11(16.42)$ & $3(12.5)$ & $11(25.58)$ & 0.76 \\
\hline \multicolumn{5}{|l|}{ Sampling season, $n(\%)$} \\
\hline Spring & $16(23.88)$ & $9(37.5)$ & $7(16.28)$ & 0.18 \\
\hline Summer & $12(17.91)$ & $3(12.5)$ & $9(20.93)$ & \\
\hline Autumn & $12(17.91)$ & $5(20.83)$ & $7(16.28)$ & \\
\hline Winter & $27(40.30)$ & $7(29.17)$ & $20(46.51)$ & \\
\hline \multicolumn{5}{|l|}{ Symptoms, $n(\%)$} \\
\hline Fever & $53(79.1)$ & $18(75)$ & $35(81.40)$ & 0.54 \\
\hline Cough & $50(74.63)$ & $18(75)$ & $32(74.42)$ & 0.96 \\
\hline Sputum & $36(53.73)$ & $14(58.33)$ & $22(51.16)$ & 0.76 \\
\hline Dyspnea & $54(80.60)$ & $19(79.17)$ & $35(81.40)$ & 1 \\
\hline Confusion/disorientation & $15(22.39)$ & $4(16.67)$ & $11(25.58)$ & 0.40 \\
\hline \multicolumn{5}{|l|}{ Laboratory findings on ICU admission } \\
\hline $\mathrm{pH}$, median (IQR) & $7.443(0.058)$ & $7.44(0.051)$ & $7.44(0.079)$ & 0.78 \\
\hline $\mathrm{PaO}_{2} / \mathrm{FiO}_{2}, \mathrm{mmHg}$, mean $\pm \mathrm{SD}$ & $181.36 \pm 78.62$ & $205.06 \pm 78.99$ & $168.13 \pm 76.14$ & 0.10 \\
\hline Procalcitonin $>1 \mathrm{ng} / \mathrm{mL}, n(\%)$ & $36(53.73)$ & $10(41.67)$ & $26(60.47)$ & 0.14 \\
\hline Creatinine $>106 \mu \mathrm{mol} / \mathrm{L}, n(\%)$ & $28(41.79)$ & $7(29.17)$ & $21(48.84)$ & 0.12 \\
\hline \multicolumn{5}{|l|}{ Initial radiographic findings, $n(\%)$} \\
\hline Diffuse bilateral pulmonary infiltration & $56(83.58)$ & $19(58.33)$ & $37(86.05)$ & 0.70 \\
\hline Pleural effusion & $25(37.31)$ & $4(16.67)$ & $21(48.84)$ & 0.009 \\
\hline \multicolumn{5}{|l|}{ Pathogen identified ${ }^{\mathrm{b}}, n(\%)$} \\
\hline Virus & $25(37.31)$ & $9(37.5)$ & $16(37.21)$ & 0.96 \\
\hline Bacteria & $12(17.91)$ & $4(16.67)$ & $8(18.60)$ & \\
\hline Viral and bacterial co-infection & $7(10.45)$ & $2(8.33)$ & $5(11.63)$ & \\
\hline Atypical pathogens ${ }^{c}$ & $9(13.43)$ & $4(16.67)$ & $5(11.63)$ & 0.84 \\
\hline Probable IFD & $8(11.94)$ & $2(8.33)$ & $6(13.95)$ & 0.77 \\
\hline \multicolumn{5}{|l|}{ Complications at sampling, $n(\%)$} \\
\hline ARDS & $29(43.28)$ & $7(29.17)$ & $22(51.16)$ & 0.08 \\
\hline Sepsis & $65(97.01)$ & $22(91.67)$ & $43(100)$ & 0.12 \\
\hline
\end{tabular}




\begin{tabular}{|c|c|c|c|c|}
\hline & & & & (Continued) \\
\hline Variable & All patients $(N=67)$ & Improvement $(n=24)$ & Unimprovement $(n=43)$ & $P$ \\
\hline Septic shock & $21(31.34)$ & $3(12.5)$ & $18(41.86)$ & 0.01 \\
\hline AKI & $23(34.33)$ & $6(25)$ & $17(39.53)$ & 0.23 \\
\hline Acute cardiac insufficiency & $15(22.39)$ & $7(29.17)$ & $8(18.60)$ & 0.32 \\
\hline Antibiotic used before sampling ${ }^{\mathrm{d}}, n(\%)$ & $67(100)$ & & & \\
\hline Carbapenems & $22(32.84)$ & $7(29.17)$ & $15(34.88)$ & 0.97 \\
\hline$\beta$-lactams plus fluoroquinolones only & $37(55.22)$ & $14(58.33)$ & $23(53.49)$ & \\
\hline$\beta$-lactams only & $5(7.46)$ & $2(8.33)$ & $3(6.98)$ & \\
\hline Fluoroquinolones only & $3(4.48)$ & $1(4.17)$ & $2(4.65)$ & \\
\hline Vancomycin $^{\mathrm{e}}$ & $11(16.42)$ & $0(0)$ & $11(25.58)$ & 0.02 \\
\hline \multicolumn{5}{|l|}{ Oxygen support before sampling, $n(\%)$} \\
\hline High-flow nasal cannula only & $26(38.81)$ & $12(50)$ & $14(32.56)$ & 0.16 \\
\hline Mechanical ventilation & $41(61.19)$ & $12(50)$ & $29(67.44)$ & \\
\hline Mechanical ventilation $\geqslant 2$ days, $n(\%)$ & $23(34.33)$ & $6(25)$ & $17(39.53)$ & 0.23 \\
\hline \multicolumn{5}{|l|}{ Severity variables at sampling } \\
\hline APACHE-II, mean \pm SD & $12.78 \pm 5.65$ & $10.17 \pm 5.76$ & $14.23 \pm 5.10$ & 0.01 \\
\hline PSI risk class IV-V, $n(\%)$ & $41(61.19)$ & $12(50)$ & $29(67.44)$ & 0.16 \\
\hline CURB-65 risk score $3-5, n(\%)$ & $26(38.81)$ & $4(16.67)$ & $22(51.16)$ & 0.005 \\
\hline \multicolumn{5}{|l|}{ 7-category ordinal scale at sampling, $n(\%)$} \\
\hline 5: Hospitalization, requiring HFNC and/or non-IMV & $42(62.69)$ & $18(75)$ & $24(55.81)$ & 0.12 \\
\hline 6: Hospitalization, requiring ECMO and/or IMV & $25(37.31)$ & $6(25)$ & $19(44.19)$ & \\
\hline Days from illness onset to admission, median (IQR) & $5(4)$ & $5.5(4.25)$ & $5(4)$ & 0.91 \\
\hline Hours from admission to sampling ${ }^{\mathrm{f}}$, median (IQR) & $21(13)$ & $21(17)$ & $21(11.5)$ & 0.79 \\
\hline \multicolumn{5}{|l|}{ ICU outcomes } \\
\hline ICU length of stay, day, median (IQR) & $9(9.5)$ & $7.5(5.5)$ & $12(10.5)$ & 0.03 \\
\hline Death in ICU, $n(\%)$ & $11(16.41)$ & $0(0)$ & $11(25.58)$ & 0.23 \\
\hline Day 14 mortality, $n(\%)$ & $8(11.94)$ & $0(0)$ & $8(18.60)$ & 0.06 \\
\hline \multicolumn{5}{|l|}{ Plasma biomarker on admission, $\mathrm{pg} / \mathrm{mL}$, mean $\pm \mathrm{SD}$} \\
\hline IL-4 & $5.64 \pm 12.6$ & $4.89 \pm 6.19$ & $6.06 \pm 15.1$ & 0.34 \\
\hline IL-6 & $336.30 \pm 725.60$ & $95.99 \pm 133.02$ & $470.42 \pm 875.35$ & 0.00 \\
\hline IL-8 & $61.50 \pm 144.24$ & $19.63 \pm 23.81$ & $84.87 \pm 175.56$ & $0.56 \times 10^{-6}$ \\
\hline MIP-1 $\beta$ & $169.01 \pm 498.12$ & $117.53 \pm 194.91$ & $197.75 \pm 605.59$ & 0.30 \\
\hline VEGF-A & $1343.97 \pm 761.88$ & $1269.44 \pm 752.93$ & $1385.56 \pm 772.50$ & 0.44 \\
\hline MMP-9 & $142.34 \pm 156.14$ & $118.01 \pm 83.77$ & $155.92 \pm 184.23$ & 0.89 \\
\hline
\end{tabular}

${ }^{a}$ Smoking status was grouped as nonsmokers, current smokers, and former smokers (defined as previous smokers who had quit at least 6 months before illness onset).

${ }^{\mathrm{b}}$ Two patients had positive urinary antigen for Streptococcus pneumoniae with negative bacteria laboratory test results in bronchoalveolar lavage fluid (BALF). Other microbiology results were obtained from the identification in BALF collected within $48 \mathrm{~h}$.

${ }^{c}$ Atypical pathogens consisted of Legionella pneumophila and Mycoplasma pneumoniae.

dOnly six patients $(8.96 \%)$ did not receive antibiotics before admission to ICU. Among the patients, two received carbapenems, and four received $\beta$-lactams plus fluoroquinolones only.

${ }^{\mathrm{e}}$ Consisting of vancomycin, teicoplanin, and linezolid.

${ }^{\mathrm{f}}$ For patients admitted to ICU on the same day, the order of performing bronchoscopy was arranged on the basis of the time sequence of signing the bronchoscopy informed consent.

Abbreviations: IFD, invasive fungal disease; ARDS, acute respiratory distress syndrome; AKI, acute kidney injury; IQR, interquartile range; SD, standard deviation; ICU, intensive care unit.

$P$ values comparing ICU care and no ICU care are obtained from $\chi^{2}$ test, Fisher's exact test, or Mann-Whitney U test.

microbiota, accounting for $43.7 \%$ of the total filtered reads, followed by Firmicutes (30.94\%), Actinobacteria (7.93\%), Bacteroidetes $(4.6 \%)$, and Fusobacteria $(1.17 \%)$. At the family level, the most abundant taxa were Pseudomonadaceae $(23.22 \%)$, Streptococcaceae $(13.71 \%)$, Pasteurellaceae $(11.33 \%)$, Corynebacteriaceae $(5.72 \%)$, Moraxellaceae $(5.15 \%)$, Staphylococcaceae (4.94\%),
Bacillaceae_1 (4.5\%), Veillonellaceae (2.98\%), Prevotellaceae $(2.1 \overline{1 \%})$, and Enterobacteriaceae (1.74\%).

\section{Clinical factors associated with lung microbiota on ICU admission}

We first performed a univariate PERMANOVA on the 


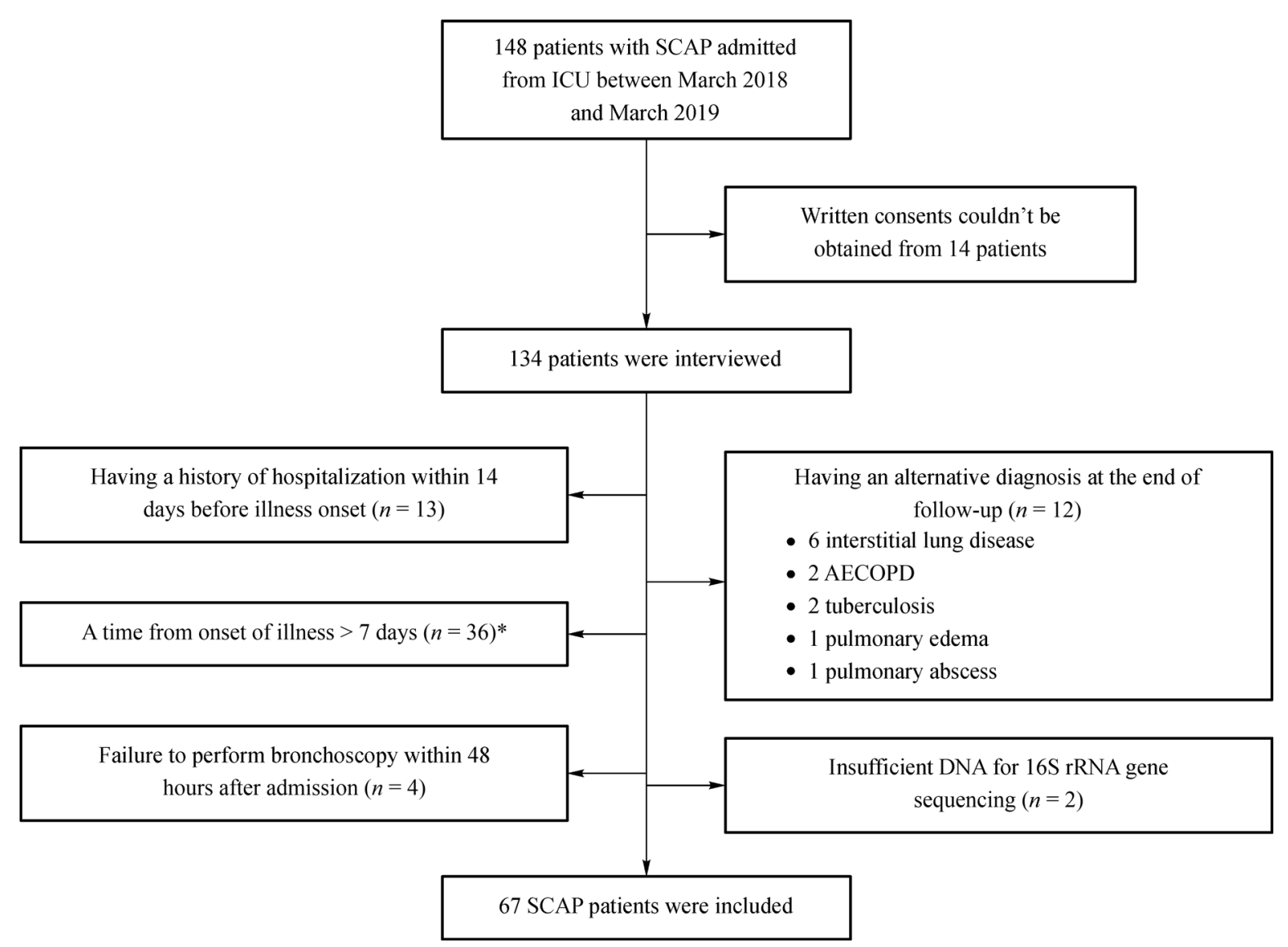

Fig. 1 Study flow chart. SCAP, severe community-acquired pneumonia; ICU, intensive care unit; AECOPD, acute exacerbation of chronic obstructive pulmonary disease. *The patients transferred to ICU from normal wards in our hospital because of disease exacerbation within 7 days of hospital admission were also included.

association between clinical factors and lung microbiota. The plasma MIP-1 $\beta$ level (Bray-Curtis distance; $\mathrm{R}^{2}=$ $0.029 ; P=0.03)$, procalcitonin $(\mathrm{PCT})$ level $\left(\mathrm{R}^{2}=0.029 ; P\right.$ $=0.026)$, complicated with AKI $\left(\mathrm{R}^{2}=0.033 ; P=0.012\right)$, positive bacteria laboratory test results $\left(\mathrm{R}^{2}=0.033 ; P=\right.$ $0.013)$, and the time from admission to sampling $\left(\mathrm{R}^{2}=\right.$ $0.049 ; P=0.018$; Fig. 2A-2E) were significantly associated with the lung microbiota based on the univariate PERMANOVA. By contrast, age, baseline chronic respiratory diseases, antibiotic use, complicated with ARDS, and septic shock (Fig. S2, Table S3) were not significantly associated with the lung microbiota.

We performed a multivariable analysis to assess the independent association of the clinical factors. Smoking status $\left(\mathrm{R}^{2}=0.036 ; P=0.185\right)$, time on mechanical ventilator before sampling $\left(\mathrm{R}^{2}=0.04 ; P=0.097\right)$, and sputum production $\left(\mathrm{R}^{2}=0.021 ; P=0.118\right.$; Fig. $\left.2 \mathrm{~F}\right)$ whose $P$ value was less than 0.2 were also included. $\kappa$ test did not show a severe multicollinearity problem among the eight factors $(\mathrm{K}=4.8$; Fig. $2 \mathrm{~F})$. The positive bacteria laboratory test results showed the strongest independent association with the lung microbiota composition (multivariable
PERMANOVA, $\mathrm{R}^{2}=0.033 ; P=0.018$ ), followed by AKI $\left(\mathrm{R}^{2}=0.032 ; P=0.011\right)$ and plasma MIP-1 $\beta$ level $\left(\mathrm{R}^{2}\right.$ $=0.027 ; P=0.044)$.

\section{Bacteria laboratory test results and lung microbial taxa}

The Prevotellaceae family played the most important role in distinguishing bacterial samples with positive bacteria laboratory test results from those with negative results, followed by the pathogenic taxa, such as, the families Moraxellaceae, Staphylococcaceae, and Streptococcaceae (Fig. 3A). In patients with positive bacteria laboratory test results, the mean relative abundance of the families Prevotellaceae, Microbacteriaceae, and Actinomycetaceae decreased, whereas the families Moraxellaceae, Staphylococcaceae, and Streptococcaceae increased (Fig. 3A and $3 \mathrm{~B})$, which were in line with their high isolation rate of typical bacterial culture (Table 2). 16S rRNA gene sequencing could produce the same results as culture methods in $61 \%$ of patients (Table 2). However, no significant difference in the relative abundance of the 

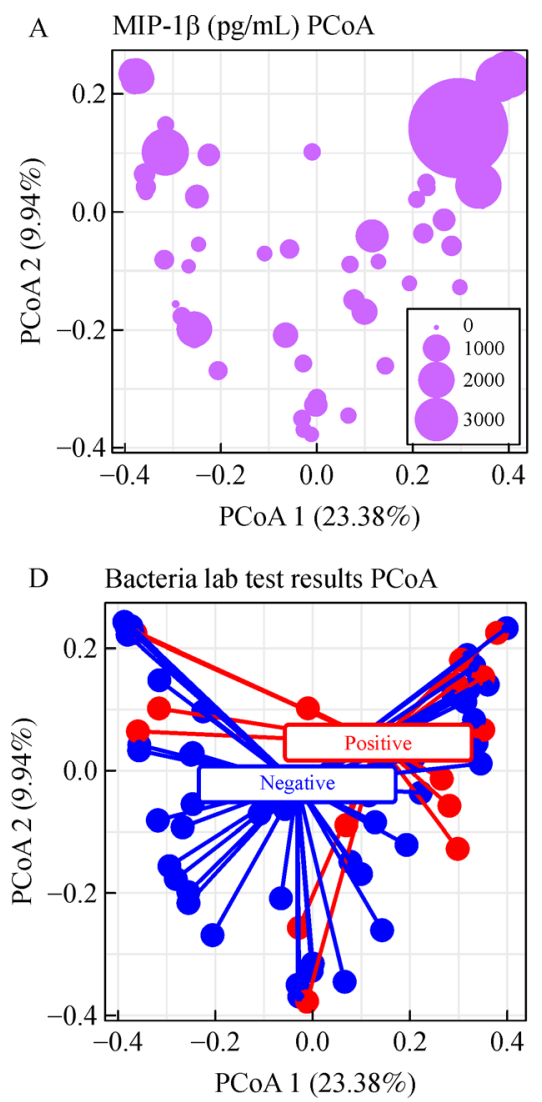

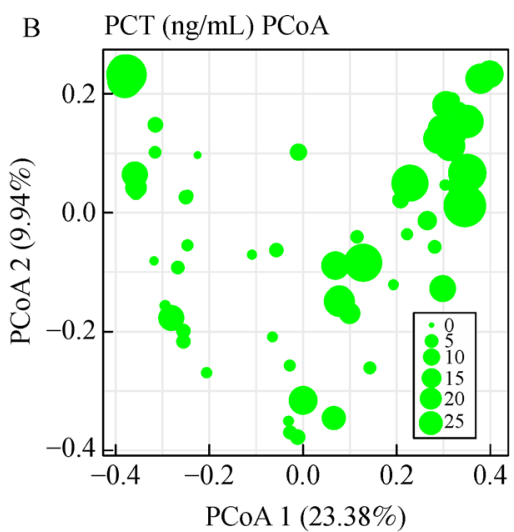

E Bronchoscopy time PCoA

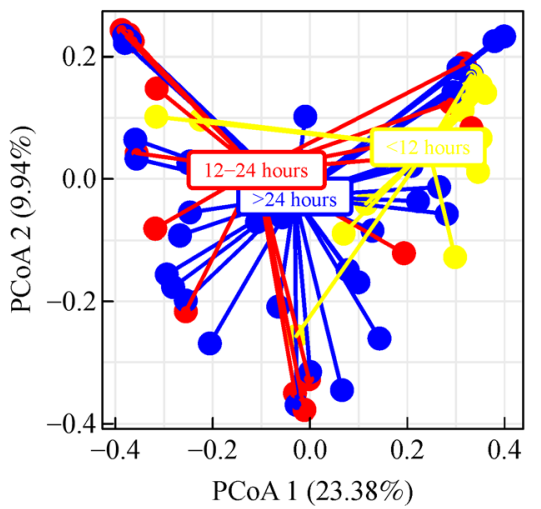

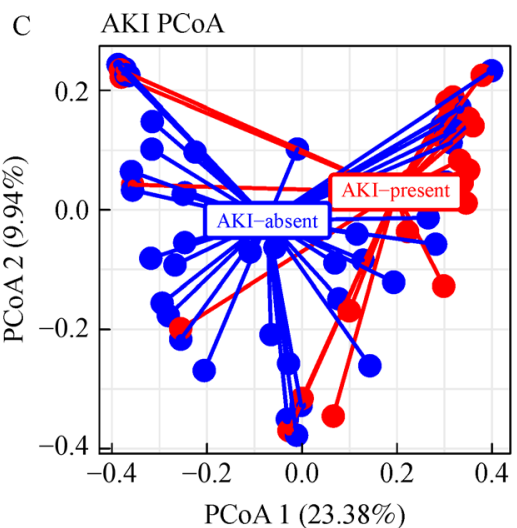

$\mathrm{F}$

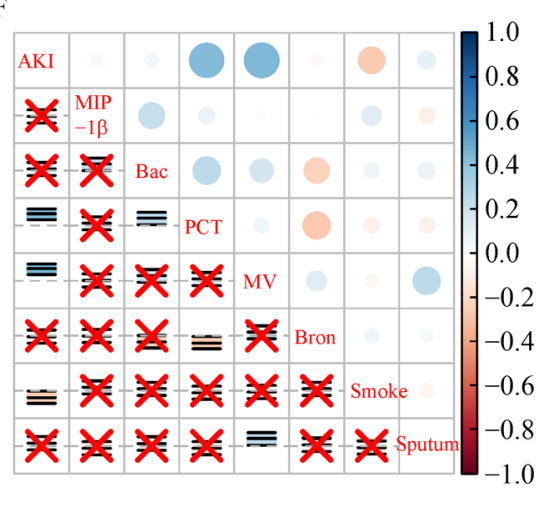

Fig. 2 Clinical factors associated with lung microbiota on ICU admission. Principal Coordinate Analysis (PCoA) plot based on BrayCurtis distance revealed that the lung microbial community composition was significantly associated with the concentration of MIP-1 $\beta$ (A) and procalcitonin (B). The lung microbiota was associated with the presence of acute kidney injury (AKI) on ICU admission (C), positive bacteria laboratory test results (D), and the time from ICU admission to sampling under bronchoscopy (E). The co-association among the eight clinical factors was calculated by Pearson correlation analysis (F). The circles were proportional to the absolute value of the correlation coefficients. The squares represented the $P$ values. "X" represented the $P$ values larger than 0.05 . AKI, acute kidney injury; PCT, procalcitonin; bac, positive bacteria laboratory test results; $\mathrm{MV}$, time on mechanical ventilator before sampling; bron, the time from ICU admission to sampling under bronchoscopy; sputum, sputum production.

family Pseudomonadaceae was observed between the two groups of patients (Fig. 3A). The samples with bacteria detected had lower $\alpha$ diversity, and the difference was not significant (Fig. 3C).

\section{Lung microbiota and clinical improvements}

The lung microbial community composition of the patients on admission was not associated with clinical improvements (PERMANOVA; Bray-Curtis distance; $\mathrm{R}^{2}=0.011$; $P=0.76)$. The increased Shannon index predicted a faster decrease of 2 categories, which was analyzed continuously (adjusted HR 1.43 , 95\% CI $1.04-1.98, P=0.03$ ) or by organizing their value into ranges (adjusted HR 5.73, 95\% CI 1.41-23.26, $P=0.01$; Fig. 4B, Table 3). Although positive bacteria laboratory test results were not associated with clinical improvement, we found that every $1 \%$ increase in the relative abundance of the families Prevotellaceae and Actinomycetaceae in the lung micro- biota of the patients increased the probability for clinical improvements by $14 \%$ and $10 \%$, respectively $(95 \% \mathrm{CI}$ $1.04-1.25, P=0.006 ; 95 \%$ CI $1.02-1.18, P=0.01$; Table 3, Fig. 4C and 4D). However, the families Moraxellaceae, Staphylococcaceae, and Streptococcaceae were not associated with clinical improvement (Table 3, Fig. 4C and 4D). The proportions of patients with ARDS, septic shock, CURB-65 $\geqslant 3$, and PSI $\geqslant$ IV were similar irrespective of the different levels of $\alpha$ diversity or relative abundance of taxa (Table S4).

\section{Discussion}

This prospective cohort study described the composition of lung microbiota and the important taxa predicting clinical prognosis in patients with SCAP. The core findings of our study indicated that positive bacteria laboratory test results had the strongest independent association with the lung 


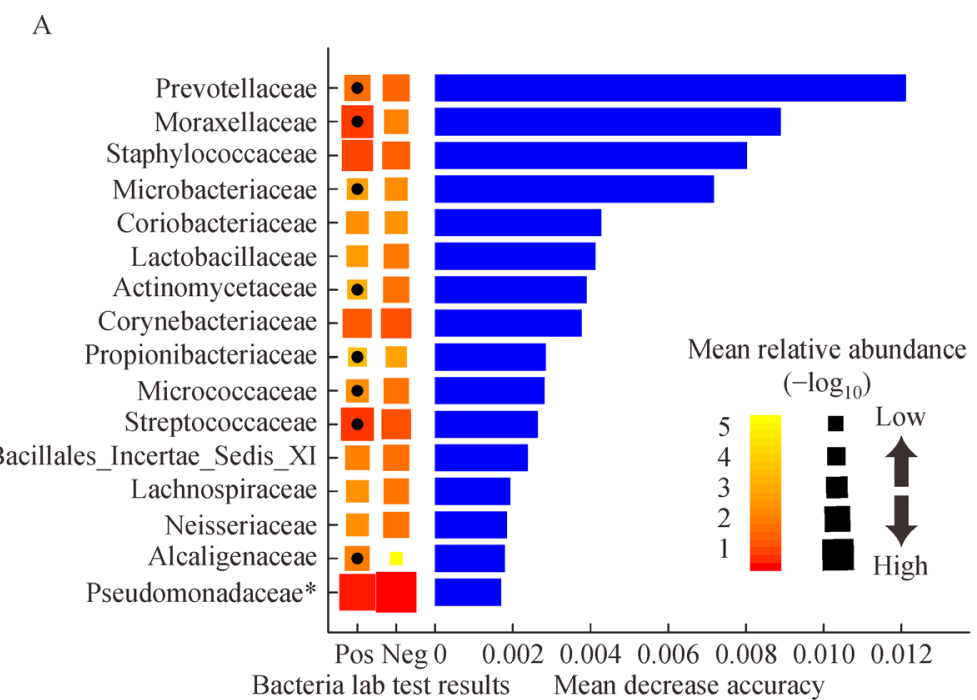

B
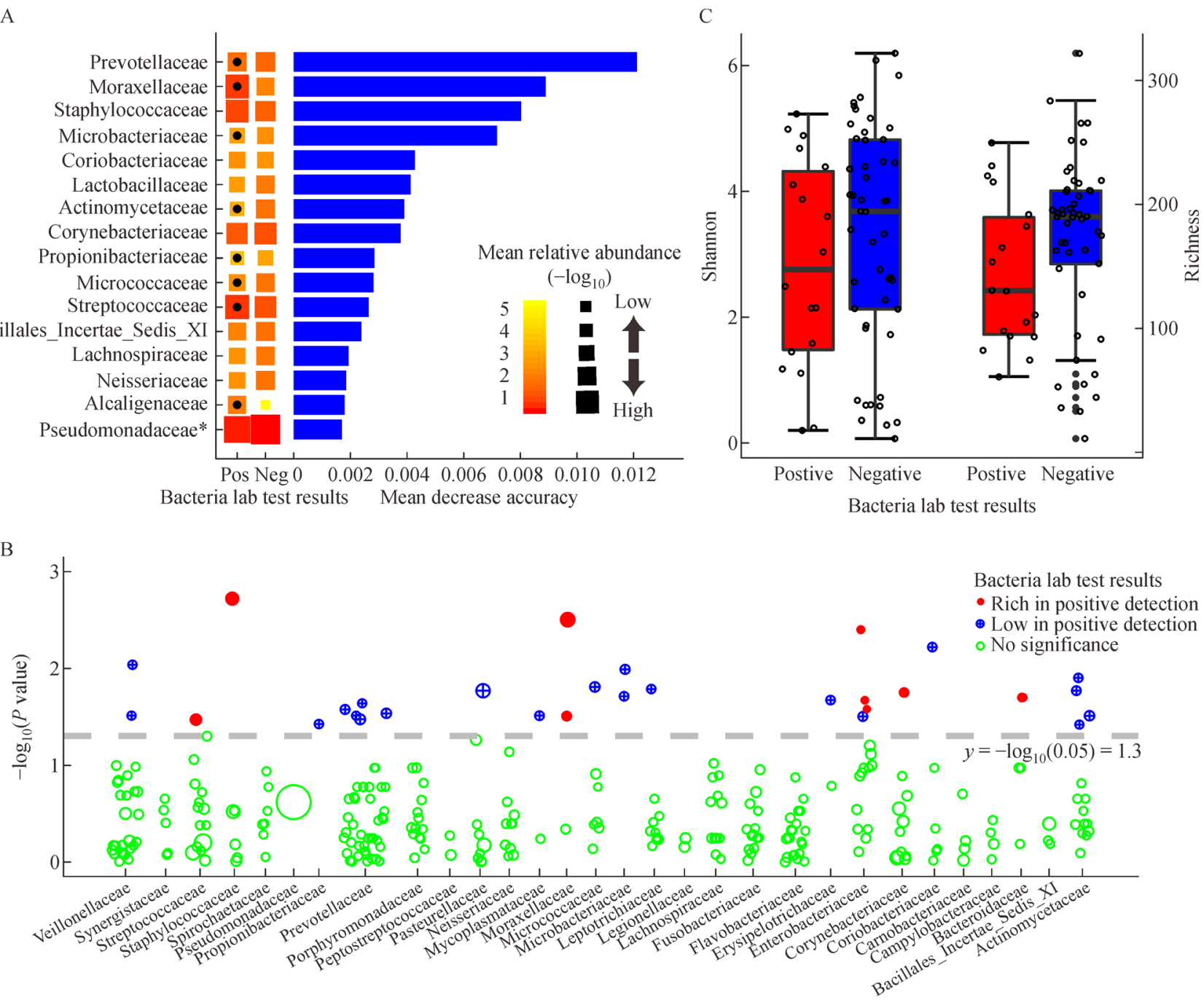

Fig. 3 Bacteria laboratory test results and lung microbial taxa. The top 15 biomarker taxa associated with positive bacteria laboratory test results were listed (A). The black points represented significant difference in the relative abundance of the species between the two groups. The squares represented the median relative abundance $\left(-\log _{10}\right)$ of the biomarker taxa across the groups. *The variation of the relative abundance in the family Pseudomonadaceae, which was not included in the top 15, was shown. (B) The positions of the ZOTUs on the $Y$-axis were determined by $-\log _{10}$ ( $P$ value from the comparison of the mean relative abundance in ZOTUs among the groups). The size of circles was proportional to the relative abundance of the ZOTUs in microbiota. (C) The boxplots represented the diversity measures (Shannon index and Richness) for the patients (center line, median; box limits, interquartile range; whisker limits, maximum/minimum).

microbiota composition on patients' ICU admission, followed by AKI and plasma MIP-1 $\beta$ level. The increased $\alpha$ diversity and the enrichment of the families Prevotellaceae and Actinomycetaceae in the lung microbiota were associated with clinical improvements.

In this study, the positive bacteria laboratory test results on admission were the most important factor associated with patients' lung microbiota. The bacteria that could be identified by the laboratory tests used in this study (primarily culture-based methods) might be more abundant in the lower respiratory tract [26]. This finding might explain why these taxa (e.g., Acinetobacter baumannii and Staphylococcus aureus) dominated the lung microbiota in patients with positive bacteria laboratory results as revealed by $16 \mathrm{~S}$ rRNA gene sequencing. Although the results of 16S rRNA sequencing and culture-based methods were consistent with regard to dominant bacteria, the results related to Pseudomonas aeruginosa differed in these two technologies. Although culture-based methods had high isolation rate $(33.33 \%)$ of Pseudomonas aeruginosa, 16S rRNA sequencing did not show a significant difference in the relative abundance of the family Pseudomonadaceae between the positive bacteria laboratory test and negative bacteria laboratory test groups. The ICU environment might be the reason behind the phenomenon. $P$. aeruginosa is a primary nosocomial 
Table 2 Comparison between positive bacteria laboratory test results and sequencing results

\begin{tabular}{lll}
\hline MV $\geqslant 2$ days $^{{ }^{2}}$ & Bacteria & The most abundant ZOTU in sequencing \\
\hline Yes & Acinetobacter baumannii & ZOTU4_f_Streptococcaceae (38.43\%) \\
Yes & Acinetobacter baumannii & ZOTU5_f_Moraxellaceae (87.82\%) \\
Yes & Acinetobacter baumannii, Klebsiella pneumoniae & ZOTU5_f_Moraxellaceae (37.71\%) \\
Yes & Pseudomonas aeruginosa & ZOTU1_f_Pseudomonadaceae (98.5\%) \\
Yes & Pseudomonas aeruginosa & ZOTU1_f_Pseudomonadaceae (83.84\%) \\
Yes & Staphylococcus aureus & ZOTU18_f_Streptococcaceae (54.3\%) \\
Yes & Staphylococcus aureus & ZOTU10_f_Staphylococcaceae (29.84\%) \\
No & Pseudomonas aeruginosa & ZOTU18_f_Streptococcaceae (13.98\%) \\
No & Pseudomonas aeruginosa & ZOTU1_f_Pseudomonadaceae (69.33\%) \\
No & Pseudomonas aeruginosa & ZOTU1_f_Pseudomonadaceae (83.92\%) \\
No & Pseudomonas aeruginosa & ZOTU1_f_Pseudomonadaceae (36.14\%) \\
No & Staphylococcus aureus & ZOTU13_f_Corynebacteriaceae (15.91\%) \\
No & Staphylococcus aureus & ZOTU10__Staphylococcaceae (59.17\%) \\
No & Streptococcus pneumoniae & ZOTU4__Streptococcaceae (98.02\%) \\
No & Streptococcus pneumoniae & ZOTU1_f_Pseudomonadaceae (27.86\%) \\
No & Acinetobacter baumannii & ZOTU5_f_Moraxellaceae (50.41\%) \\
No & Klebsiella pneumoniae & ZOTU59_f_Bacteroidaceae (12.28\%) \\
No & Escherichia coli & ZOTU44_f_Corynebacteriaceae (13.28\%)
\end{tabular}

${ }^{a}$ The patients who had more than 2 days on ventilator were defined as "Yes," and those who had less than 2 days or never received mechanical ventilation were defined as "No."

${ }^{\mathrm{b}}$ Two patients had positive urinary antigen for Streptococcus pneumoniae with negative bacteria laboratory test results in bronchoalveolar lavage fluid (BALF). ${ }^{\mathrm{c}}$ The relative abundance of the most abundant ZOTU was shown.

The bold font represented different results between positive bacteria laboratory test results and sequencing results.

Abbreviation: MV, mechanical ventilation.

pathogen in ICU. The risk factors for P. aeruginosa acquisition consisted of antibiotic pressure, mechanical ventilation use, length of hospitalization, cross-transmission among patients and medical staffs, and environmental factors, such as contamination of tap water [27-29]. All of our patients had received antimicrobial treatments, and more than half were exposed to mechanical ventilation before bronchoscopy. Thus, these patients might have the same risk of obtaining $P$. aeruginosa colonization under the ICU status. Although 16S rRNA gene sequencing had a low accuracy for pathogen identification, it could capture all the information related to bacterial species, including fastidious bacteria in the respiratory tract, which might explain the different results between culture-dependent and culture-independent analysis in our study [30,31].

AKI was common in SCAP patients [32]. Many studies had suggested a complex cross-talk between the lung and the kidney [33]. Cigarette smoking could induce endothelial cell injury with increased AGEs-RAGE levels in the lung and kidney [34]. In critically ill patients, mechanical ventilation was proven to be a risk factor for AKI by a meta-analysis [34]. A study in mice with sepsis established by cecal ligation and puncture showed that ventilatorinduced lung injury increased the renal expression of VEGF, VCAM-1, and angiopoietin-2 [35]. In our study, we observed that the presence of AKI on admission was associated with lung microbiota of the patients. However, few studies described the effect of AKI on lung microbiota. The plasma MIP-1 $\beta$ level was significantly associated with the abundance of the Streptococcaceae family. In vitro experiments confirmed that $S$. pneumoniae D39 could induce the upregulation of MIP-1 $\beta$ gene in human monocytes [36]. Similar conclusions, that is, the increased level of MIP-1 $\beta$ in BALF was related to the enrichment of $S$. pneumoniae in the lung microbiota, were drawn from patients with asthma [37]. The enrichment of Streptococcus spp. in the lung microbiota was associated with high plasma MIP-1 $\beta$ level in our patients. The ZOTU4, belonging to the family Streptococcaceae, was significantly higher in the high MIP-1 $\beta$ level group (Fig. S3).

In our study, after adjustment for microbiology results and severity of illness, multivariate analysis showed that clinical improvements were associated with increased relative abundance of the families Prevotellaceae and Actinomycetaceae. The results of our study were supported by several previous studies. Based on previous studies, the relative abundance of Prevotella was inversely associated with the extent of airway inflammation in patients with cystic fibrosis [38]. An increase in the abundance of Prevotella in nose/throat microbiota was related to lower susceptibility to influenza A infection [39]. As the families Prevotellaceae and Actinomycetaceae usually resided in the healthy respiratory tract or oral cavity [40-42], the protective role of these families might 

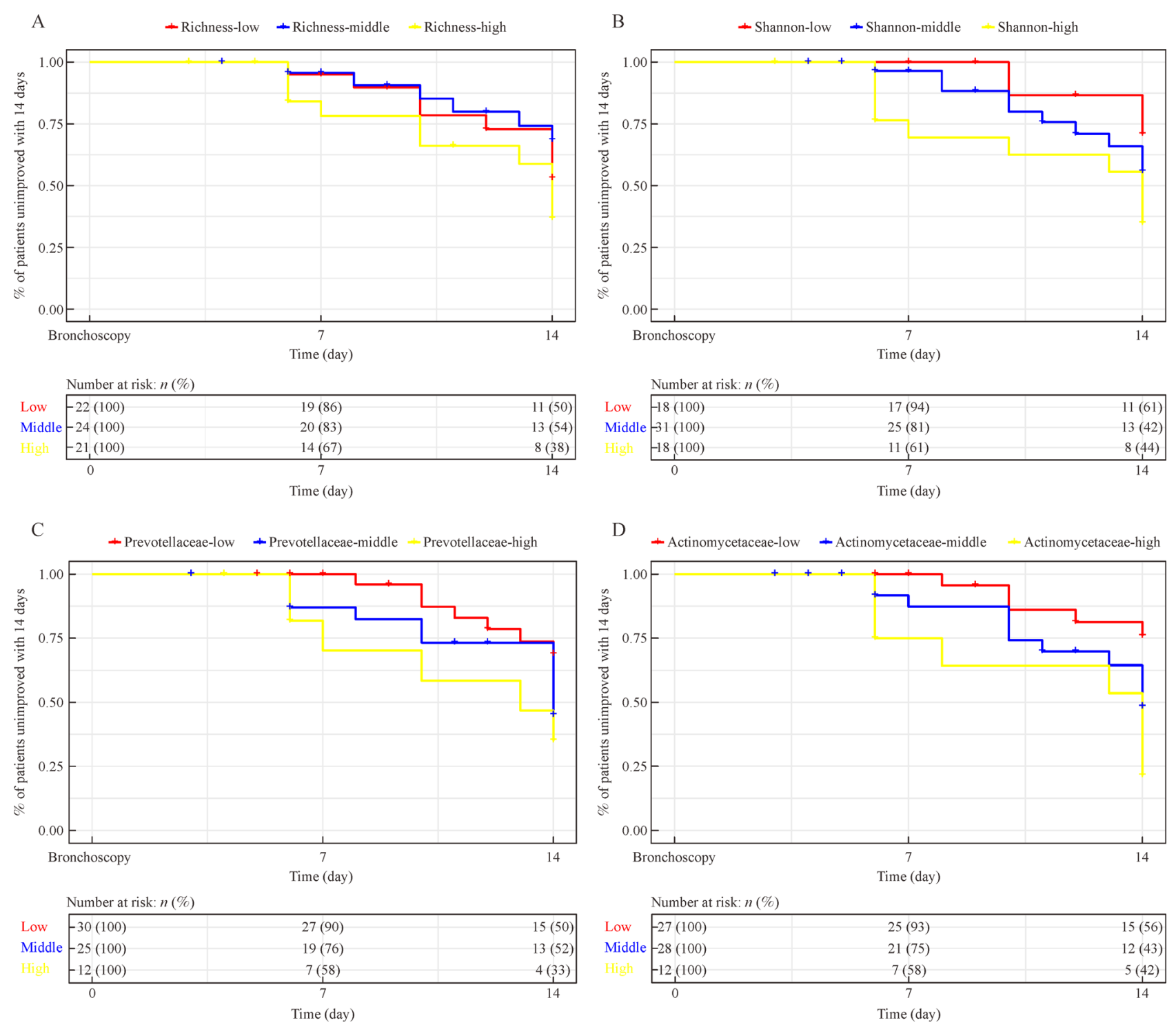

Fig. 4 Lung microbiota and clinical improvements. Survival curves were plotted using the Kaplan-Meier method. The primary outcome was the rate of clinical improvements (defined as a decrease of 2 categories and above on a 7-category ordinal scale) within 14 days following bronchoscopy. Richness (A), Shannon index (B), and the relative abundance of the families Prevotellaceae (C) and Actinomycetaceae (D) were protective of the clinical improvements after adjusting for sampling season, plasma IL-8 level, CURB-65, APACHEII scores, presence of shock at sampling, oxygen index on admission, creatinine level, and microbiology results. The categorical cut-offs were consistent with those in Table 3.

stem from its ability to inhibit the growth of pathogenic bacteria. For example, coculture experiments observed that Prevotella spp. could inhibit Hemophilus influenzaeinduced IL-12p70 in dendritic cells [43]. Nevertheless, another set of research showed that the enrichment of lung microbiota with Prevotella enhanced the level of BALF inflammatory cytokines, which was associated with the development of asthma in children and ARDS in severe patients $[13,40,44]$. The findings in current studies appeared to be inconsistent probably because of the observational nature and potential confounders in these studies. In addition, the disease type and population in these studies were different, and the result of current studies had limited generalizability. Therefore, the actual role of these taxa in disease severity and prognosis of patients with respiratory diseases should be further explored.

Different from some respiratory microbiome studies in critically ill patients, our study found that the composition of lung microbiota at sampling was not associated with the presence of ARDS or septic shock. For example, unlike the report in two previous published studies $[13,14]$, the 
Table 3 Association of lung microbiota with clinical improvements in multivariable analysis

\begin{tabular}{|c|c|c|c|}
\hline Variable & Adjusted $\mathrm{HR}^{\mathrm{a}}$ & $95 \% \mathrm{CI}$ & $P$ value \\
\hline \multicolumn{4}{|l|}{ Pathogen identified $^{b}$} \\
\hline Bacteria only & Reference & & \\
\hline Viral-bacterial co-infection & 0.37 & $0.04-3.20$ & 0.37 \\
\hline Virus & 0.90 & $0.18-4.60$ & 0.90 \\
\hline Others & 0.79 & $0.21-3.02$ & 0.73 \\
\hline Richness (continuous) & 1.01 & $1.00-1.02$ & 0.17 \\
\hline \multicolumn{4}{|l|}{ Richness (categorical) ${ }^{\mathrm{c}}$} \\
\hline$<150$ & Reference & & \\
\hline $199-150$ & 0.65 & $0.15-2.87$ & 0.57 \\
\hline$\geqslant 200$ & 3.51 & $0.84-14.64$ & 0.08 \\
\hline Shannon (continuous) & 1.43 & $1.04-1.98$ & 0.03 \\
\hline \multicolumn{4}{|l|}{ Shannon (categorical) ${ }^{\mathrm{c}}$} \\
\hline$<2$ & Reference & & \\
\hline $4.5-2$ & 2.65 & $0.73-9.67$ & 0.14 \\
\hline$>4.5$ & 5.73 & $1.41-23.26$ & 0.01 \\
\hline Prevotellaceae, $1 \%^{\mathrm{d}}$ (continuous) & 1.14 & $1.04-1.25$ & 0.006 \\
\hline \multicolumn{4}{|l|}{ Prevotellaceae, $\%$ (categorical) ${ }^{\mathrm{c}}$} \\
\hline$<0.3$ & Reference & & \\
\hline $2.4-0.3$ & 3.54 & $1.06-11.84$ & 0.04 \\
\hline$>2.4$ & 8.58 & $2.15-34.26$ & 0.002 \\
\hline Actinomycetaceae, $1 \%$ (continuous) & 1.10 & $1.02-1.18$ & 0.01 \\
\hline \multicolumn{4}{|l|}{ Actinomycetaceae, $\%$ (categorical) $^{\mathrm{c}}$} \\
\hline$<0.005$ & Reference & & \\
\hline $0.5-0.005$ & 2.40 & $0.74-7.77$ & 0.15 \\
\hline$>0.5$ & 10.25 & $2.77-37.87$ & 0.0005 \\
\hline Moraxellaceae, $1 \%$ (continuous) & 1.00 & $0.96-1.04$ & 0.89 \\
\hline Staphylococcaceae, $1 \%$ (continuous) & 0.98 & $0.94-1.03$ & 0.40 \\
\hline Streptococcaceae, $1 \%$ (continuous) & 1.01 & $0.99-1.04$ & 0.35 \\
\hline Pseudomonadaceae, $1 \%$ (continuous) & 0.99 & $0.98-1.01$ & 0.23 \\
\hline Enterobacteriaceae, $1 \%$ (continuous) & 0.95 & $0.78-1.15$ & 0.58 \\
\hline
\end{tabular}

${ }^{a}$ Multiple cox regression analysis adjusted for sample season, plasma IL-8 level, CURB-65, APACHEII scores, presence of shock at sampling, oxygen index on admission, creatinine level, and microbiology results.

${ }^{b}$ Multiple cox regression analysis adjusted for sample season, plasma IL-8 level, CURB-65, APACHEII scores, presence of shock at sampling, oxygen index on admission, and creatinine level.

${ }^{\mathrm{c}}$ We changed the continuous variables into categorical variables by organizing their values into ranges. First, according to the value of the variable, 67 samples were arranged in order. Second, we divided the samples into 10 groups evenly. Finally, we combined the neighboring groups that had the similar probability for the event happened.

${ }_{\mathrm{d}} 1 \%$ referred to the probability for clinical improvements of every $1 \%$ increase in the relative abundance of taxa.

Abbreviations: HR, hazard ratio; CI, confidence interval.

relative abundance of the family Enterobacteriaceae was not associated with disease severity and clinical outcomes in our study probably because these studies primarily focused on patients with ARDS caused by severe trauma, cardiac arrest, or cerebral vascular events but not severe infection. In Robert P. Dickson et al.'s study, patients with pneumonia or sepsis merely accounted for $13 \%$ (12/91), and in Ariane R. Panzer's study, the ARDS in patients was due to trauma $[13,14]$. Thus, the conclusions of the studies might not be applied to SCAP patients.

Our study has several limitations. First, the lung microbiota analysis was only performed on ICU admission. The variation of lung microbiota during patients' hospitalization and the association of lung microbiota with clinical improvements could not be analyzed. Second, the sample size of the included patients was small compared with studies for other diseases. Further studies are needed to validate the conclusions.

\section{Conclusions}

In this study on respiratory microbiome of SCAP patients, we found that the positive bacteria laboratory test results, AKI, and plasma MIP-1 $\beta$ level were associated with the composition of lung microbiota on patients' ICU admis- 
sion. The increased $\alpha$ diversity and the enrichment of the families Prevotellaceae and Actinomycetaceae in the lung microbiota were associated with clinical improvements.

\section{Acknowledgements}

This study was funded by the National Key Research and Development Program of China (No. 2017YFC1309301), the CAMS Innovation Fund for Medical Sciences (CIFMS; No. 2018I2M-1-003), the National Science Grant for Distinguished Young Scholars (No. 81425001/H0104), and the Ministry of Science and Technology of China (No. 2017ZX10103004).

\section{Compliance with ethics guidelines}

Sisi Du, Xiaojing Wu, Binbin Li, Yimin Wang, Lianhan Shang, Xu Huang, Yudi Xia, Donghao Yu, Naicong Lu, Zhibo Liu, Chunlei Wang, Xinmeng Liu, Zhujia Xiong, Xiaohui Zou, Binghuai Lu, Yingmei Liu, Qingyuan Zhan, and Bin Cao declare that they have no competing interests. Our study was conducted in China-Japan Friendship Hospital, Beijing, China, and approved by the ChinaJapan Friendship Hospital Ethics Committee (Approval No. 201820-K15). It was conducted in accordance with the he Helsinki Declaration of 1975, as revised in 2000 (5). We obtained written informed consent from all enrolled patients or their legal representative for patients who were unable to provide consent.

Electronic Supplementary Material Supplementary material is available in the online version of this article at https://doi.org/ $10.1007 / \mathrm{s} 11684-021-0856-3$ and is accessible for authorized users.

\section{References}

1. Liapikou A, Rosales-Mayor E, Torres A. The management of severe community acquired pneumonia in the intensive care unit. Expert Rev Respir Med 2014; 8(3): 293-303

2. Espinoza R, Silva JRLE, Bergmann A, de Oliveira Melo U, Calil FE, Santos RC, Salluh JIF. Factors associated with mortality in severe community-acquired pneumonia: a multicenter cohort study. J Crit Care 2019; 50: 82-86

3. Phua J, Dean NC, Guo Q, Kuan WS, Lim HF, Lim TK. Severe community-acquired pneumonia: timely management measures in the first 24 hours. Crit Care 2016; 20(1): 237

4. Li HY, Guo Q, Song WD, Zhou YP, Li M, Chen XK, Liu H, Peng HL, Yu HQ, Chen X, Liu N, Lü ZD, Liang LH, Zhao QZ, Jiang M. Mortality among severe community-acquired pneumonia patients depends on combinations of 2007 IDSA/ATS minor criteria. Int J Infect Dis 2015; 38: 141-145

5. Torres A, Chalmers JD, Dela Cruz CS, Dominedò C, Kollef M, Martin-Loeches I, Niederman M, Wunderink RG. Challenges in severe community-acquired pneumonia: a point-of-view review. Intensive Care Med 2019; 45(2): 159-171

6. Charlson ES, Bittinger K, Haas AR, Fitzgerald AS, Frank I, Yadav A, Bushman FD, Collman RG. Topographical continuity of bacterial populations in the healthy human respiratory tract. Am J Respir Crit Care Med 2011; 184(8): 957-963

7. Zakharkina T, Martin-Loeches I, Matamoros S, Povoa P, Torres A, Kastelijn JB, Hofstra JJ, de Wever B, de Jong M, Schultz MJ, Sterk PJ, Artigas A, Bos LDJ. The dynamics of the pulmonary microbiome during mechanical ventilation in the intensive care unit and the association with occurrence of pneumonia. Thorax 2017; 72(9): 803-810

8. Dickson RP, Erb-Downward JR, Huffnagle GB. Towards an ecology of the lung: new conceptual models of pulmonary microbiology and pneumonia pathogenesis. Lancet Respir Med 2014; 2(3): 238-246

9. Dickson RP, Erb-Downward JR, Martinez FJ, Huffnagle GB. The microbiome and the respiratory tract. Annu Rev Physiol 2016; 78 (1): 481-504

10. Dickson RP. The microbiome and critical illness. Lancet Respir Med 2016; 4(1): 59-72

11. Brown RL, Sequeira RP, Clarke TB. The microbiota protects against respiratory infection via GM-CSF signaling. Nat Commun 2017; 8 (1): 1512

12. Pettigrew MM, Gent JF, Kong Y, Wade M, Gansebom S, Bramley AM, Jain S, Arnold SLR, McCullers JA. Association of sputum microbiota profiles with severity of community-acquired pneumonia in children. BMC Infect Dis 2016; 16(1): 317

13. Panzer AR, Lynch SV, Langelier C, Christie JD, McCauley K, Nelson M, Cheung CK, Benowitz NL, Cohen MJ, Calfee CS. Lung microbiota is related to smoking status and to development of acute respiratory distress syndrome in critically ill trauma patients. Am J Respir Crit Care Med 2018; 197(5): 621-631

14. Dickson RP, Schultz MJ, van der Poll T, Schouten LR, Falkowski NR, Luth JE, Sjoding MW, Brown CA, Chanderraj R, Huffnagle GB, Bos LDJ; Biomarker Analysis in Septic ICU Patients (BASIC) Consortium. Lung microbiota predict clinical outcomes in critically ill patients. Am J Respir Crit Care Med 2020; 201(5): 555-563

15. Nair GB, Niederman MS. Updates on community acquired pneumonia management in the ICU. Pharmacol Ther 2021; 217: 107663

16. Mandell LA, Wunderink RG, Anzueto A, Bartlett JG, Campbell GD, Dean NC, Dowell SF, File TM Jr, Musher DM, Niederman MS, Torres A, Whitney CG; Infectious Diseases Society of America; American Thoracic Society. Infectious Diseases Society of America/ American Thoracic Society consensus guidelines on the management of community-acquired pneumonia in adults. Clin Infect Dis 2007; 44(Suppl 2): S27-S72

17. Interventional Pulmonology Group of the Chinese Thoracic Society, Chinese Medical Association. Guideline for diagnostic flexible bronchoscopy in adults (2019). Chin J Tuberc Respir Dis (Zhonghua Jie He He Hu Xi Za Zhi) 2019; 42(8): 573-590 (in Chinese)

18. Cao B, Wang Y, Wen D, Liu W, Wang J, Fan G, Ruan L, Song B, Cai Y, Wei M, Li X, Xia J, Chen N, Xiang J, Yu T, Bai T, Xie X, Zhang L, Li C, Yuan Y, Chen H, Li H, Huang H, Tu S, Gong F, Liu Y, Wei Y, Dong C, Zhou F, Gu X, Xu J, Liu Z, Zhang Y, Li H, Shang L, Wang K, Li K, Zhou X, Dong X, Qu Z, Lu S, Hu X, Ruan S, Luo S, Wu J, Peng L, Cheng F, Pan L, Zou J, Jia C, Wang J, Liu X, Wang S, Wu X, Ge Q, He J, Zhan H, Qiu F, Guo L, Huang C, Jaki T, Hayden FG, Horby PW, Zhang D, Wang C. A trial of lopinavirritonavir in adults hospitalized with severe Covid-19. N Engl J Med 2020; 382(19): 1787-1799 
19. Wang Y, Fan G, Horby P, Hayden F, Li Q, Wu Q, Zou X, Li H, Zhan Q, Wang C, Cao B; CAP-China Network. Comparative outcomes of adults hospitalized with seasonal influenza A or B virus infection: application of the 7-category ordinal scale. Open Forum Infect Dis 2019; 6(3): ofz053

20. Wang Y, Zhang D, Du G, Du R, Zhao J, Jin Y, Fu S, Gao L, Cheng Z, Lu Q, Hu Y, Luo G, Wang K, Lu Y, Li H, Wang S, Ruan S, Yang C, Mei C, Wang Y, Ding D, Wu F, Tang X, Ye X, Ye Y, Liu B, Yang J, Yin W, Wang A, Fan G, Zhou F, Liu Z, Gu X, Xu J, Shang L, Zhang Y, Cao L, Guo T, Wan Y, Qin H, Jiang Y, Jaki T, Hayden FG, Horby PW, Cao B, Wang C. Remdesivir in adults with severe COVID-19: a randomised, double-blind, placebo-controlled, multicentre trial. Lancet 2020; 395(10236): 1569-1578

21. Zhou F, Wang Y, Liu Y, Liu X, Gu L, Zhang X, Pu Z, Yang G, Liu B, Nie Q, Xue B, Feng J, Guo Q, Liu J, Fan H, Chen J, Zhang Y, Xu Z, Pang M, Chen Y, Nie X, Cai Z, Xu J, Peng K, Li X, Xiang P, Zhang Z, Jiang S, Su X, Zhang J, Li Y, Jin X, Jiang R, Dong J, Song Y, Zhou H, Wang C, Cao B; CAP-China Network. Disease severity and clinical outcomes of community-acquired pneumonia caused by non-influenza respiratory viruses in adults: a multicentre prospective registry study from the CAP-China Network. Eur Respir J 2019; 54 (2): 1802406

22. Ferguson ND, Fan E, Camporota L, Antonelli M, Anzueto A, Beale R, Brochard L, Brower R, Esteban A, Gattinoni L, Rhodes A, Slutsky AS, Vincent JL, Rubenfeld GD, Thompson BT, Ranieri VM. The Berlin definition of ARDS: an expanded rationale, justification, and supplementary material. Intensive Care Med 2012; 38(10): 1573-1582

23. Singer M, Deutschman CS, Seymour CW, Shankar-Hari M, Annane D, Bauer M, Bellomo R, Bernard GR, Chiche JD, Coopersmith CM, Hotchkiss RS, Levy MM, Marshall JC, Martin GS, Opal SM, Rubenfeld GD, van der Poll T, Vincent JL, Angus DC. The Third International Consensus Definitions for Sepsis and Septic Shock (Sepsis-3). JAMA 2016; 315(8): 801-810

24. Khwaja A. KDIGO clinical practice guidelines for acute kidney injury. Nephron Clin Pract 2012; 120(4): c179-c184

25. Donnelly JP, Chen SC, Kauffman CA, Steinbach WJ, Baddley JW, Verweij PE, Clancy CJ, Wingard JR, Lockhart SR, Groll AH, Sorrell TC, Bassetti M, Akan H, Alexander BD, Andes D, Azoulay E, Bialek R, Bradsher RW Jr, Bretagne S, Calandra T, Caliendo AM, Castagnola E, Cruciani M, Cuenca-Estrella M, Decker CF, Desai SR, Fisher B, Harrison T, Heussel CP, Jensen HE, Kibbler CC, Kontoyiannis DP, Kullberg BJ, Lagrou K, Lamoth F, Lehrnbecher T, Loeffler J, Lortholary O, Maertens J, Marchetti O, Marr KA, Masur H, Meis JF, Morrisey CO, Nucci M, Ostrosky-Zeichner L, Pagano L, Patterson TF, Perfect JR, Racil Z, Roilides E, Ruhnke M, Prokop CS, Shoham S, Slavin MA, Stevens DA, Thompson GR III, Vazquez JA, Viscoli C, Walsh TJ, Warris A, Wheat LJ, White PL, Zaoutis TE, Pappas PG. Revision and update of the consensus definitions of invasive fungal disease from the European Organization for Research and Treatment of Cancer and the Mycoses Study Group Education and Research Consortium. Clin Infect Dis 2020; 71(6): 1367-1376

26. Kelly BJ, Imai I, Bittinger K, Laughlin A, Fuchs BD, Bushman FD, Collman RG. Composition and dynamics of the respiratory tract microbiome in intubated patients. Microbiome 2016; 4(1): 7

27. Venier AG, Leroyer C, Slekovec C, Talon D, Bertrand X, Parer S,
Alfandari S, Guerin JM, Megarbane B, Lawrence C, Clair B, Lepape A, Perraud M, Cassier P, Trivier D, Boyer A, Dubois V, Asselineau J, Rogues AM, Thiébaut R; DYNAPYO study group. Risk factors for Pseudomonas aeruginosa acquisition in intensive care units: a prospective multicentre study. J Hosp Infect 2014; 88(2): 103-108

28. Hoang S, Georget A, Asselineau J, Venier AG, Leroyer C, Rogues AM, Thiébaut R. Risk factors for colonization and infection by Pseudomonas aeruginosa in patients hospitalized in intensive care units in France. PLoS One 2018; 13(3): e0193300

29. Bachta KER, Allen JP, Cheung BH, Chiu CH, Hauser AR. Systemic infection facilitates transmission of Pseudomonas aeruginosa in mice. Nat Commun 2020; 11(1): 543

30. Hilton SK, Castro-Nallar E, Pérez-Losada M, Toma I, McCaffrey TA, Hoffman EP, Siegel MO, Simon GL, Johnson WE, Crandall KA. Metataxonomic and metagenomic approaches vs. culture-based techniques for clinical pathology. Front Microbiol 2016; 7: 484

31. Emonet S, Lazarevic V, Leemann Refondini C, Gaïa N, Leo S, Girard M, Nocquet Boyer V, Wozniak H, Després L, Renzi G, Mostaguir K, Dupuis Lozeron E, Schrenzel J, Pugin J. Identification of respiratory microbiota markers in ventilator-associated pneumonia. Intensive Care Med 2019; 45(8): 1082-1092

32. Chawla LS, Amdur RL, Faselis C, Li P, Kimmel PL, Palant CE. Impact of acute kidney injury in patients hospitalized with pneumonia. Crit Care Med 2017; 45(4): 600-606

33. Husain-Syed F, Slutsky AS, Ronco C. Lung-kidney cross-talk in the critically ill patient. Am J Respir Crit Care Med 2016; 194(4): 402414

34. Polverino F, Laucho-Contreras ME, Petersen H, Bijol V, Sholl LM, Choi ME, Divo M, Pinto-Plata V, Chetta A, Tesfaigzi Y, Celli BR, Owen CA. A pilot study linking endothelial injury in lungs and kidneys in chronic obstructive pulmonary disease. Am J Respir Crit Care Med 2017; 195(11): 1464-1476

35. Hepokoski M, Englert JA, Baron RM, Crotty-Alexander LE, Fuster MM, Beitler JR, Malhotra A, Singh P. Ventilator-induced lung injury increases expression of endothelial inflammatory mediators in the kidney. Am J Physiol Renal Physiol 2017; 312(4): F654-F660

36. Rogers PD, Thornton J, Barker KS, McDaniel DO, Sacks GS, Swiatlo E, McDaniel LS. Pneumolysin-dependent and-independent gene expression identified by cDNA microarray analysis of THP-1 human mononuclear cells stimulated by Streptococcus pneumoniae. Infect Immun 2003; 71(4): 2087-2094

37. Turturice BA, McGee HS, Oliver B, Baraket M, Nguyen BT, Ascoli C, Ranjan R, Rani A, Perkins DL, Finn PW. Atopic asthmatic immune phenotypes associated with airway microbiota and airway obstruction. PLoS One 2017; 12(10): e0184566

38. Zemanick ET, Wagner BD, Robertson CE, Ahrens RC, Chmiel JF, Clancy JP, Gibson RL, Harris WT, Kurland G, Laguna TA, McColley SA, McCoy K, Retsch-Bogart G, Sobush KT, Zeitlin PL, Stevens MJ, Accurso FJ, Sagel SD, Harris JK. Airway microbiota across age and disease spectrum in cystic fibrosis. Eur Respir J 2017; 50(5): 1700832

39. Tsang TK, Lee KH, Foxman B, Balmaseda A, Gresh L, Sanchez N, Ojeda S, Lopez R, Yang Y, Kuan G, Gordon A. Association between the respiratory microbiome and susceptibility to influenza virus infection. Clin Infect Dis 2020; 71(5): 1195-1203

40. Segal LN, Clemente JC, Tsay JC, Koralov SB, Keller BC, Wu BG, 
Li Y, Shen N, Ghedin E, Morris A, Diaz P, Huang L, Wikoff WR, Ubeda C, Artacho A, Rom WN, Sterman DH, Collman RG, Blaser MJ, Weiden MD. Enrichment of the lung microbiome with oral taxa is associated with lung inflammation of a Th17 phenotype. Nat Microbiol 2016; 1(5): 16031

41. Morris A, Beck JM, Schloss PD, Campbell TB, Crothers K, Curtis JL, Flores SC, Fontenot AP, Ghedin E, Huang L, Jablonski K, Kleerup E, Lynch SV, Sodergren E, Twigg H, Young VB, Bassis CM, Venkataraman A, Schmidt TM, Weinstock GM; Lung HIV Microbiome Project. Comparison of the respiratory microbiome in healthy nonsmokers and smokers. Am J Respir Crit Care Med 2013; 187(10): 1067-1075

42. Li X, Sun Y, An Y, Wang R, Lin H, Liu M, Li S, Ma M, Xiao C. Air pollution during the winter period and respiratory tract microbial imbalance in a healthy young population in Northeastern China. Environ Pollut 2019; 246: 972-979

43. Larsen JM, Steen-Jensen DB, Laursen JM, Søndergaard JN, Musavian HS, Butt TM, Brix S. Divergent pro-inflammatory profile of human dendritic cells in response to commensal and pathogenic bacteria associated with the airway microbiota. PLoS One 2012; 7 (2): e31976

44. Thorsen J, Rasmussen MA, Waage J, Mortensen M, Brejnrod A, Bønnelykke K, Chawes BL, Brix S, Sørensen SJ, Stokholm J, Bisgaard H. Infant airway microbiota and topical immune perturbations in the origins of childhood asthma. Nat Commun 2019; 10(1): 5001 